\title{
Rheological behavior of waste polypropylene reinforced with zinc oxide nanoparticles
}

\author{
N. J. Hadi, N. A. Saad \& D. Alkhfagy \\ College of Materials Engineering/Polymer, Babylon University, Iraq
}

\begin{abstract}
The present paper investigates the influences of $\mathrm{ZnO}$ nanoparticles on the rheological behavior of waste polypropylene and their relationship with surface morphology. The modified composites are composed of waste polypropylene and $\mathrm{ZnO}$ nanoparticles in the content of 3, 5, 7 and 10 weight percentages. Two techniques are used to incorporate nanoparticles in the polypropylene matrix. The first one uses an ultrasonic device to distribute nanoparticles in an alcohol solvent and the second uses a rotating twin screw extruder at $25 \mathrm{rpm}$ and at $190^{\circ} \mathrm{C}$ to produce a polymer nanocomposite sheet. Different microstructure and morphological techniques (X-ray diffraction XRD and field emission scanning electron microscopy FESEM) are used to evaluate the effect of the additive percentage ( $\mathrm{ZnO}$ nanoparticles) and processing technique (ultrasonic and twin screw extruder) on the microstructure and morphology of the nanocomposite. Also, various rheological (melt flow rate MFR and melt volume rate MVR) and physical (solid and melt density) properties are studied. The results of the XRD test show that the crystallinity level increases with the increase in $\mathrm{ZnO}$ nanoparticle percentage while the results of FESEM show that the sonication process and twin screw extruder gradually reduces the agglomeration of $\mathrm{ZnO}$ nanoparticles in the polypropylene matrix. The results of the rheological test show that there is an improvement in the viscosity of the nanocomposite (decreasing in MFR and MVR) with the increase in $\mathrm{ZnO}$ nanoparticle percentage. Also, the density results show a big difference between the solid and melt states.

Keywords: waste polypropylene, ZnO nanoparticles, MFR and MVR, flow behavior, twin screw extruder.
\end{abstract}




\section{Introduction}

The wide use of polymeric materials creates the problem of a growing quantity of waste and the possibility of using recycled materials is limited because of the poor properties of recycled plastics compared to virgin ones. One of the possibilities of improving the properties of plastic products is using diverse fillers, such as $\mathrm{CaCO}_{3}, \mathrm{TiO}_{2}$ and $\mathrm{ZnO}$ [1].

The recycling of plastic materials is strategically very important for the environmental policy of industry. This is especially true for high consumption plastics, such as polypropylene (PP). The key factor in the success of PP is its versatility, which is due to the fact that the structure and properties of PP can be designed to satisfy the requirements [2].

Polypropylene is a trading widely used thermoplastic polymer, which offers the best price/performance characteristics among all thermoplastics. It has useful properties, including high thermal stability and good mechanical properties, dimensional stability, low density, better process ability, high water permeation resistance and resistance to corrosion [3]. A great volume percent of PP blends, used in fiber and fabric technology and composites, are used in a wide range of applications such as automotive parts, extruded profiles, cable insulation, footwear, medical (syringes) and the packaging industry [4].

In recent years, the incorporation of nanoparticles in a PP matrix has gained extreme importance among polymer scientists due to its promising industrial applications in many aspects of technology. Nanocomposites with good filler dispersion offer significant improvements in mechanical, thermal, electrical, optical and physicochemical properties even at relatively low filler content [5].

Nanocomposites are a new class of mineral-field plastics that contain relatively small amounts $(<10 \%)$ of nanometer-sized clay particles [6]. The particles, due to their extremely high aspect ratios (about 100-15000), and high surface area (in excess of $750-800 \mathrm{~m}^{2} / \mathrm{g}$ ) promise to improve structural, mechanical, flame retardant, thermal and barrier properties [7].

$\mathrm{ZnO}$ is one multifunctional compound that has attracted increasing attention in recent years due to its prominent properties, such as chemical stability, high luminous transmittance, high catalyst activity, effective antibacterial, intensive ultraviolet and infrared absorption, high melting temperature and non-toxicity. The advance of $\mathrm{ZnO}$ nanoparticles could improve the mechanical and optical properties of a polymer matrix [8].

The enhanced properties are due to the effects of the nanoscale structure and interaction of fillers with polymers. The size and structure of the dispersed phase significantly influence the properties of a polymer nanocomposite [9]. The key factors for the preparation of improved performance are the fine particle size and homogeneous dispersion of the nanopowders and a strong interface adhesion between matrix and nanofillers [10].

Rheology is a branch of physics that deals with the deformation and flow of matter under stress. It is particularly concerned with the properties of matter that determine its behavior when a mechanical force is exerted on it. Rheological properties have important implications in many and diverse applications [11]. 
The relationship between the structure and rheology of a polymer is of practical interest for two reasons: firstly, rheological properties are very sensitive to certain aspects of structure and they are simpler to use than analytical methods, such as nuclear magnetic resonance. Secondly, it is the rheological properties that govern the flow behavior of polymers when they are processed in the molten state [12]. Melt flow rate is defined as the mass of polymer, in grams, flowing in ten minutes through a capillary of a specific diameter and length under certain conditions of pressure and temperature (g/10min) [12].

This paper aims to produce nanocomposite materials from waste polypropylene as matrix with the addition of $\mathrm{ZnO}$ nanoparticles by using a rotating twin screw extruder at $25 \mathrm{rpm}$ and $190^{\circ} \mathrm{C}$, and to observe the effects of nanoparticle content and processing technique on sample properties, e.g. MFR, MVR and viscosity and physical properties (solid and melt density).

\section{Materials and methods}

Waste polypropylene (G-801), with a melt flow rate of $25 \mathrm{~g} / 10 \mathrm{~min}$ and a density of (902-906) kg/m $\mathrm{m}^{3}$ was used as matrix resin. $\mathrm{ZnO}$ nanoparticles are used as reinforcing phase, the main specifications of these nanoparticles are (particle size $40 \mathrm{~nm}$ and density $3.6 \mathrm{~g} / \mathrm{cm}^{3}$ ). The modified composite of waste polypropylene pellets and $\mathrm{ZnO}$ nanoparticles are prepared in two stages. The first one mixes the $\mathrm{ZnO}$ nanoparticles in alcohol using ultrasonic power at $30 \mathrm{~min}, 40^{\circ} \mathrm{C}$ and the applied energy is $30 \%$ of the total energy $(1400 \mathrm{~W})$ to reduce the agglomeration and the second stage uses a rotating twin screw extruder (SLJ model), with a screw speed in the range of $(0-320) \mathrm{rpm}$ and a diameter of $30 \mathrm{~mm}$, heating power $(3 \mathrm{KW})$ at $25 \mathrm{rpm}$ and $190^{\circ} \mathrm{C}$.

\section{Characterizations}

\subsection{Nanoparticle distribution}

Atomic Force Microscopy (AFM) version (AA3000) was used to check the morphology and particle size in two and three dimensions. The $\mathrm{ZnO}$ nanoparticles are dispersed in alcohol by using an ultrasonic device under the condition $\left(30 \mathrm{~min}, 40^{\circ} \mathrm{C}\right.$ and the applied energy is $30 \%$ of the total energy " 1200 watt"), then using the standard method for testing the thin film of nanosolution.

Also, X-ray diffraction (XRD) was used to show the crystallinity levels of the nanocomposite and check the composition and crystallite size of $\mathrm{ZnO}$ nanoparticles based on the Scherer equation as shown below

$$
\mathrm{D}=0.9 \lambda / \beta \cos \theta
$$

where $\mathrm{D}$ is the crystallite size, the $\lambda$ diffraction wavelength equals $(0.1541 \mathrm{~nm})$, $\beta$ is the full width at half maximum which must be in rads and $\theta$ is the diffraction angle. 


\subsection{Surface morphology and distribution of nanoparticles}

The surface morphology and distribution of nanoparticles through the waste polypropylene was tested by field emission scanning electron microscopy (FESEM), (model MIRA 3 XM4, USA).

\subsection{Rheological properties (MFR and MVR)}

Melt indexer type (Shi Jia Zhuang Zhong Shi Testing Machine Co. Ltd.) according to the standard of (ISO1133:2005) was used to measure the (MFR and MVR) of neat waste polypropylene and its nanocomposite through capillary die with diameter (Dc is $2.095 \mathrm{~mm}$ ) and the ratio of the die length (L) to capillary die is $(8 / 2.095)$. Solid density test was performed at room temperature using the (Matsu Haku high precision density tester GP-120S D=0.0001 g/ $\mathrm{cm}^{3}$ ), while the melt density of materials is the ratio of MFR to MVR according to the following formula [13]:

$$
\text { melt density }\left(\rho^{\prime}\right)=\frac{\text { MFR }}{\text { VR }}
$$

where $\rho^{\prime}$ : melt density, MFR: melt flow rate and MVR: melt volume rate values.

\section{Results and discussion}

\subsection{Nanoparticle distribution evaluation}

Figure 1 shows the topography of the surface of the thin film prepared of $\mathrm{ZnO}$ nanoparticle dispersion in an alcohol solvent using an ultrasonic device. It illustrates the accuracy of the ultrasonic device to produce a good dispersion and to reduce the agglomeration of nanoparticles (as shown in figure 1A) which shows the nanoparticles with a different shape but most of it has a spherical shape with a mean diameter $(20-90 \mathrm{~nm})$. Also, in figure $1 \mathrm{~B}$, the particle size distribution in bulk solution (3-D) shows the needle shape of nanoparticles in alcohol solvents. In figure $1 \mathrm{C}$ the nanoparticle size in the nanoscale range is very clear. From previous results it can illustrate the activity of an ultrasonic device in reducing the agglomeration and giving a better distribution of nanoparticles.

Another inspection to evaluate the size of nanoparticles is XRD based on the Scherer equation. Figure 2 shows the XRD for standard $\mathrm{ZnO}$ nanoparticles which was used to compare with the used $\mathrm{ZnO}$ nanoparticles. The XRD pattern in Figure 5 illustrates that the used nanoparticles from (Shijiazhuang Sun Power Technology Co. Ltd, Chain) were zinc oxide by analyzing it and comparing with the standard $\mathrm{ZnO}$. The diffraction patterns consist of the main diffraction peaks at around $2 \theta\left(31.6^{\circ}, 34.4^{\circ}, 36.2^{\circ}, 47.5^{\circ}, 56^{\circ}, 62^{\circ}, 66.3^{\circ}, 67.8^{\circ}, 69^{\circ}, 72.5^{\circ}, 76.9^{\circ}\right)$, the main peak at $2 \theta=36.2^{\circ}$. This is in agreement with standard XRD peaks for $\mathrm{ZnO}$ nanoparticles. The average crystallite size of nanoparticles based on eqn (1) in figure 3 is approximately $65 \mathrm{~nm}$. 


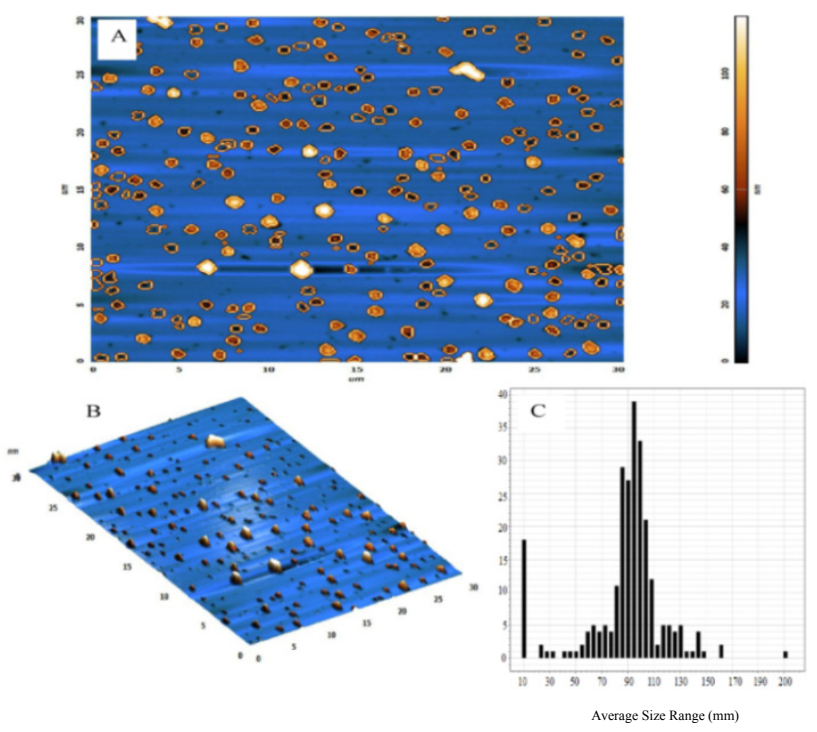

Figure 1: AFM images for the morphology of $\mathrm{ZnO}$ nanoparticles: $\mathrm{A}-2-\mathrm{D}$ particle size; B - 3-D particle size; $\mathrm{C}$ - particle size distribution.
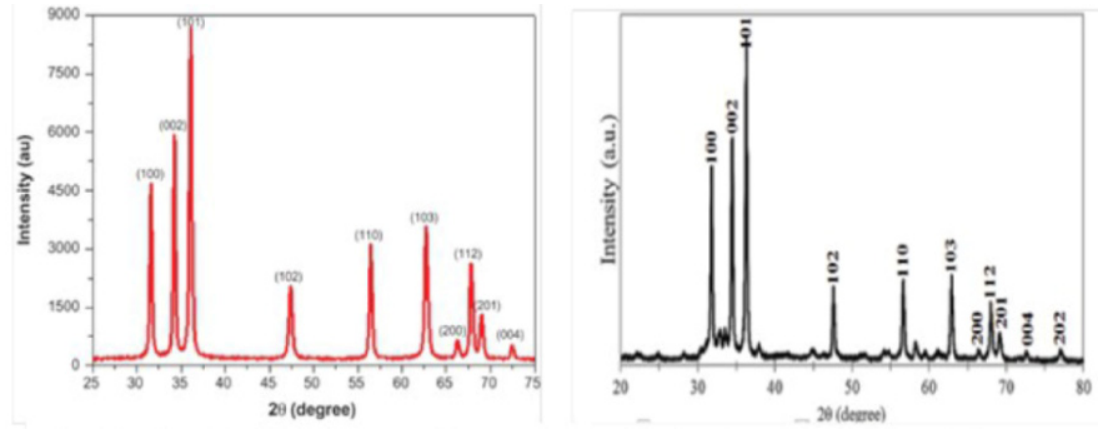

Figure 2: $\quad$ Standard $\mathrm{XRD}$ for $\mathrm{ZnO}$ Figure 3: $\mathrm{XRD}$ for used $\mathrm{ZnO}$ nanoparticles. nanoparticles.

\subsection{Crystallinity of the nanocomposite}

The crystallinity level was performed using an XRD test according to the sharpness and the intensity of the appearing peaks. Figure 4 shows the crystallinity levels of neat waste polypropylene and its nanocomposite with a different weight percentage of $\mathrm{ZnO}$ nanoparticles (5 and 10). It is very clear that the crystallinity level increases as the nanoparticle percentage increases and new peaks appear at $2 \theta\left(30^{\circ}-40^{\circ}\right)$ which mean the exits of $\mathrm{ZnO}$ nanoparticles through 
the polypropylene matrix and acts as a filler. The increase of crystallinity level is very important in improving all properties of the nanocomposite.
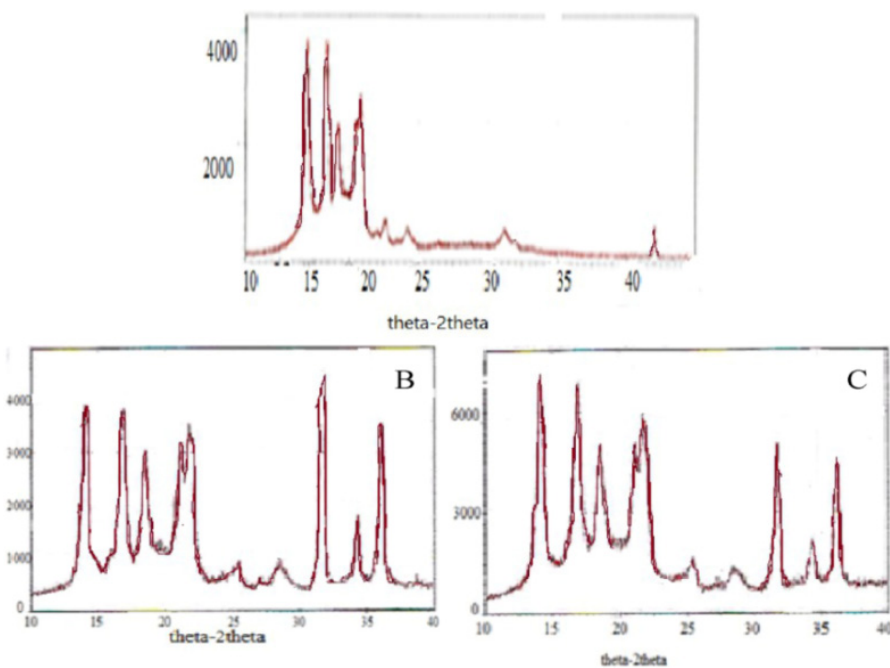

Figure 4: The crystallinity level of nanocomposite: $\mathrm{A}$ - neat waste PP; B - 5\% $\mathrm{ZnO}$ nanoparticles; $\mathrm{C}-10 \% \mathrm{ZnO}$ nanoparticles.

\subsection{Nanoparticle distribution in a modified composite}

The dispersion of the nanoparticles will have a significant effect on all the properties of the nanocomposite. The morphology of the nanocomposite was evaluated by FESEM to observe the distribution of nanoparticles within the polypropylene matrix.

Figure 5 shows the micrographs of a fractured surface of a Charpy impact of waste PP composite filled with (3 and $10 \mathrm{wt} . \%$ ) of $\mathrm{ZnO}$. It was obvious that the
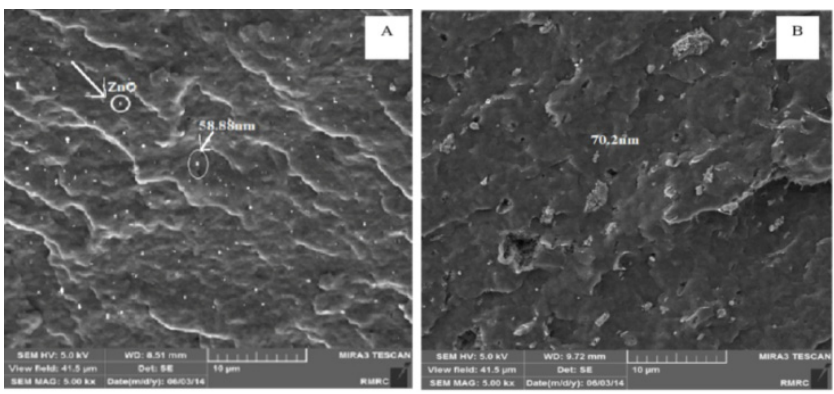

Figure 5: The microstructure image of the nanocomposite: $\mathrm{A}$ and $\mathrm{B}$ (3 and 10 wt.\%) $\mathrm{ZnO}$ nanoparticles filled waste PP. 
fracture surface of the nanocomposite sample was smooth and featureless and that the agglomeration increases with an increase in nanoparticle content because of the high specific surface area and the good dispersion of nanoparticles giving a strong interaction between nanoparticles and polymer matrix.

\subsection{Effect of nanoparticle percentage on the rheological behavior of waste PP}

\subsubsection{Melt flow rate (MFR)}

The effect of loads on MFR values of waste PP nanocomposite at different $\mathrm{ZnO}$ nanoparticle percentage and different loads at $25 \mathrm{rpm}$ and $190^{\circ} \mathrm{C}$ are shown in figure 6. The MFR slightly decreases with $\mathrm{ZnO}$ nanoparticle percentage increasing at different loads. The MFR increases with increasing loads due to the higher shear rate as a result of higher pressure and the MFR is directly proportional to the shear rate. The MFR inversely changes with the viscosity; therefore the shear rate increases with the decrease in viscosity. This is called the shear thinning effect and approximately fits with the Power Law (Ostwald) nonNewtonian viscosity model [14]

$$
\eta=K \gamma^{\cdot n-1}
$$

where $\eta$ is viscosity (Pa.s) $\gamma \cdot$ is the shear rate ( $\left.\mathrm{s}^{-1}\right) . \mathrm{K}$ is refers to the consistency of the material $\left(\mathrm{Pa} \mathrm{s}^{\mathrm{n}}\right), \mathrm{n}$ is the Power Law index, $\mathrm{n}<1$, the fluid exhibits shearthinning properties [14].

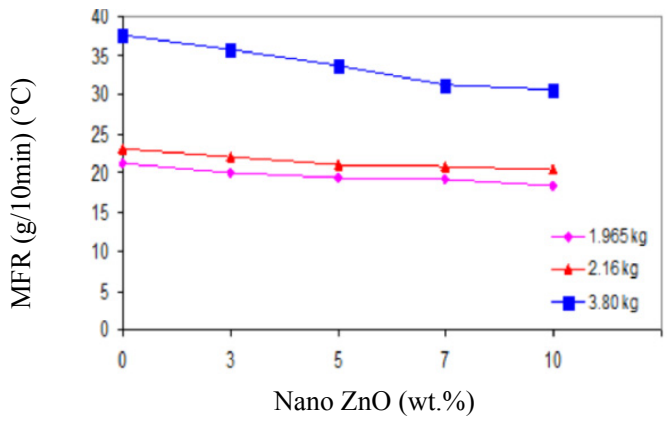

Figure 6: The MFR behaviour of waste PP nanocomposite with different loads and $\mathrm{ZnO}$ nanoparticles percentage at $(25 \mathrm{rpm})$ and $190^{\circ} \mathrm{C}$.

Another factor that influences the MFR of polymer is temperature. Figure 7 shows that the MFR increases as the temperature increases because the chain begins to move easily with the increase in free volume around the molecules as a result of the temperature rise. 


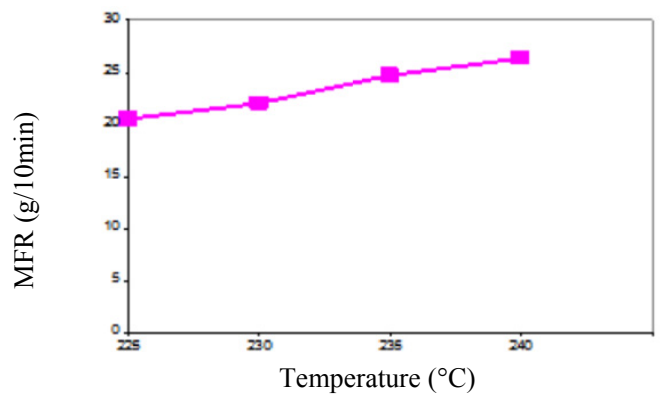

Figure 7: The behaviour of MFR of $3 \%$ of $\mathrm{ZnO}$ nanocomposite with different temperatures.

\subsubsection{Viscosity}

There are many factors that influence polymer melt viscosity, such as pressure, temperature, shear rate and polymer structure, etc. In this paper it can show the effect of temperature and pressure on the viscosity value of a polymer nanocomposite by using eqn (4). The viscosity shear rate relationship is shown according to MFR data in figure 8 . The viscosity is calculated from the following equation [12]:

$$
\eta=4.98 * 10^{4} \rho \mathrm{L} / \mathrm{MFR}
$$

where $\eta$ : the viscosity (Pa.s), $\rho$ : the density $\left(\mathrm{g} / \mathrm{cm}^{3}\right)$, and L: the loads $(\mathrm{kg})$.

The results show that the viscosity increases as the $\mathrm{ZnO}$ nanoparticles percentage increases because the interaction between nanoparticles and the chains of waste PP polymer may increase the viscosity and reduce the flexibility of movement. The increase in viscosity is confirmed with the decreasing MFR. The viscosity inversely changes with the shear rate which increases the shear thinning effect.

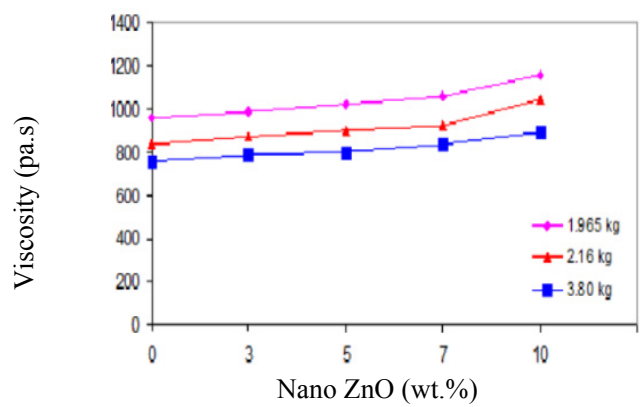

Figure 8: The viscosity behaviour of nanocomposite at different $\mathrm{ZnO}$ nanoparticle percentages and different loads.

Using the data of MFR at figure 7 can predicate the effect of temperature on the viscosity of waste PP nanocomposites with $3 \% \mathrm{ZnO}$ nanoparticles (as shown 
in figure 9). This behavior fitted with Arrhenius law, which deals with the viscosity temperature relationship of liquid and polymer melts, depending on the concept of free volume. The Arrhenius law takes the form:

$$
\eta=\eta_{\circ} e^{-E a . / R T}
$$

where $\eta_{\mathrm{o}}$ is a pre-exponential constant, $\mathrm{E}_{\mathrm{a}}$. is the apparent energy of activation, $\mathrm{R}$ is the gas constant $(\mathrm{J} / \mathrm{mol} . \mathrm{k}), \mathrm{T}$ is the temperature $(\mathrm{K})[14]$.

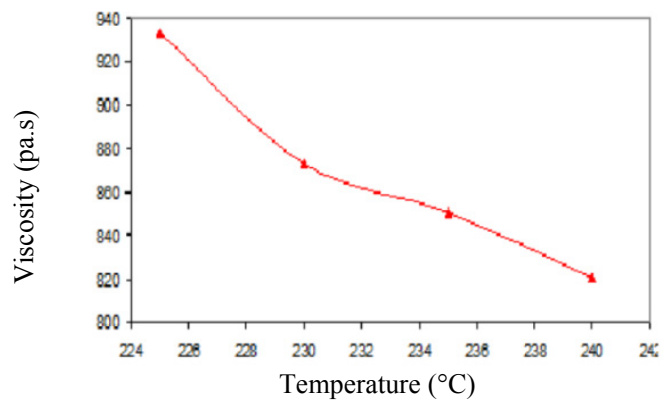

Figure 9: The viscosity behaviour of waste PP nanocomposites at different $\mathrm{ZnO}$ nanoparticle percentage, $2.16 \mathrm{~kg}$ and $190^{\circ} \mathrm{C}$ at $25 \mathrm{rpm}$.

\subsubsection{Melt volume rate (MVR)}

Figure 10 shows the MVR value for waste PP nanocomposites due to $\mathrm{ZnO}$ nanoparticle content at constant time and at 6 distances. It can be absorbed that the decrease in MVR with the increase in $\mathrm{ZnO}$ nanoparticle percentage because of the addition of $\mathrm{ZnO}$ nanoparticles may hinder the chain motion. Thus, the viscosity increases and the MFR and MVR inversely changes with viscosity. Therefore, the MVR decreases with the increase in $\mathrm{ZnO}$ nanoparticle percentage.

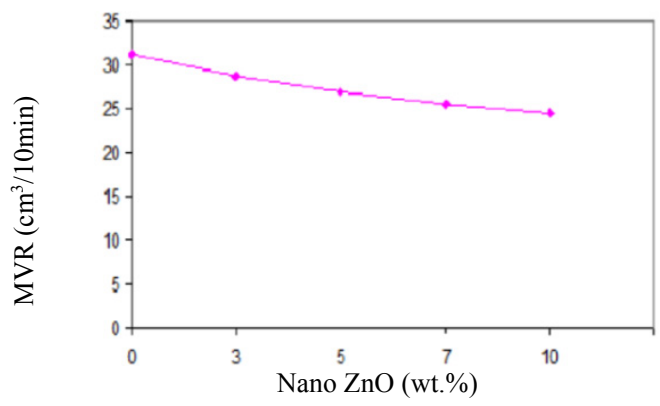

Figure 10: The MVR behaviour of waste PP nanocomposites with different $\mathrm{ZnO}$ nanoparticle percentage at $2.16 \mathrm{~kg}$ and $230^{\circ} \mathrm{C}$. 


\subsubsection{Density}

Density results for waste PP nanocomposites are shown in figure 11. The solid and melt density gradually increases as the $\mathrm{ZnO}$ nanoparticle percentage increases. This is due to a higher density of $\mathrm{ZnO}$ nanoparticles $-3.6 \mathrm{~g} / \mathrm{cm}^{3}$.

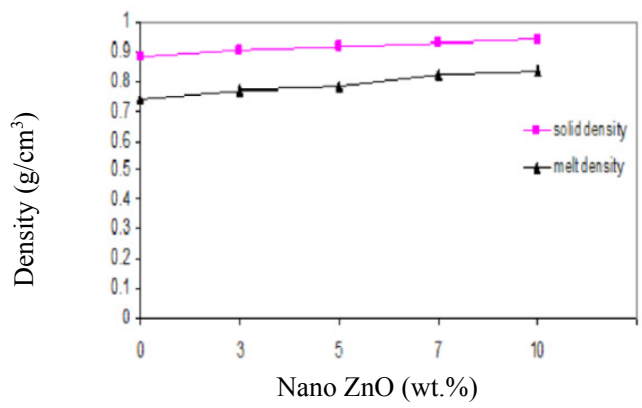

Figure 11: The solid and melt density behaviour of a waste PP nanocomposite with different $\mathrm{ZnO}$ nanoparticle percentages.

The melt density is less than the solid-state density by about $20 \%$, due to the change in volume between solid and melt state. The melt polymer has a volume higher solid polymer. The melt density is very important data for a numerical simulation study of rheological and flow behaviour. The polymer process strongly depends on the melt density which affects the manufacturing operation. The use of melt density instead of solid density produces accurate results in a numerical study and reduces costs in the manufacturing process.

\section{Conclusions}

Using an ultrasonic and twin screw extruder device are very important techniques for producing a better distribution of nanoparticles in a polymer matrix and less agglomeration. The uniformity of nanoparticle distribution strongly affects the rheological and physical properties of a melt nanocomposite. The value of the MFR and MVR plays a very important role in determining the melt density; it is a lower value than the solid-state density that is typically provided on the data sheets. There is a relationship between agglomeration of nanoparticles with crystallinity levels and the rheological properties of a waste PP nanocomposite, when agglomeration reduces the increase in crystallinity and the MFR and MVR is reduced as the viscosity increases. The melt flow rate and melt volume rate keep stable (decreasing as $\mathrm{ZnO}$ nanoparticle content increases).

\section{References}

[1] J. Aurrekoetxea, M.A. Sarrionandia, I. Urrutibeascoa \& M.L. Maspoch Effects of Injection Molding Induced Morphology on the Fracture Behavior of Virgin and Recycled Polypropylene, Polymer, 44, pp. 69596964, 2003. 
[2] Sylvie Pimbert, Ahmed Elloumi \& Alain Bourmaud Nanofillers Improve the Mechanical Properties of Recycled Polypropylene, Society of Plastics Engineers (SPE), 2010.

[3] Sharma S.K. \& S.K. Nayak Surface Modified Clay/Polypropylene (PP) Nanocomposites: Effect on Physico-Mechanical, Thermal and Morphological Properties, Polymer Degradation and Stability, 94, pp. 132-138, 2009.

[4] Wei Han, Zhen Li, Zai-Qin Wang \& Hua-Quan Yang Preparation and Mechanical Properties of Polypropylenel Maleic Anhydride Compatibilized Polypropylene/Organo-Vermiculite Nanocomposites, Polymer Plastics Technology and Engineering, pp. 374-378, 2009.

[5] Ong Hui Lin, Hazizan Md Akil, \& Shahrom Mahmud, Effect of Particle Morphology on the Properties of Polypropylene/Nano metric Zinc Oxide (pp./ZnO) Composites, Advanced Composites Letters, 18, 3, 2009.

[6] Metin Karabulut Production and Characterization of Nanocomposite Materials from Recycled Thermoplastic, A Thesis Submitted to the Graduate School of Natural and Applied Science of Middle East Technology University, 2003.

[7] Zhou J. P., Qiu K. Q. \& Fu W. L., The Surface Modification of ZnO and its Effect on the Mechanical Properties of Filled Polypropylene Composites, Composite Material, pp. 1931-1941, 2005.

[8] Thitipong Sanitchai Effect of Shape and Size of Zinc Oxide on Properties of Polypropylene with and Without, Compatibilizer, Thesis submitted in partial fulfillment of the requirements for the degree master of engineering, Silpakorn University, 2010.

[9] Tang J., Wang Y. and Liu H. \& Belfiore L. A. Effects of Organic Nucleating Agents and Zinc Oxide Nanoparticles on Isotactic Polypropylene Crystallization, Polymer, 45, pp. 2081-2091, 2004.

[10] Huang C. K., S. W. Chen \& Wei W. C. J. Processing and Property Improvement of Polymeric Composites with Added $\mathrm{ZnO}$ Nanoparticles through Microinjection Molding, Journal of Applied Polymer Science, pp. 6009-6016, 2006.

[11] Oluranti Sadiku-Agboola, Emmauel Rotimi Sadiku, Adesola Taoreed Adegbola \& Olusesan Frank Biotidara Rheological Properties of Polymers: Structure and Morphology of Molten Polymer Blends, Materials Sciences and Applications, pp. 30-41, 2011.

[12] Shenoy A. V. \& Saini D. R. Thermoplastic Melt Rheology and Processing copyright by Marcel Dekker Inc, 1996.

[13] ISO 1133 Plastics - Determination of the Melt Mass-Flow Rate (MFR) and Melt Volume-Flow Rate (MVR) of Thermoplastics, 2005.

[14] Hamdy Abu Ali Hassan Study and Optimization of Heat Transfers during Injection Molding, Analysis of their Influence on the Final Properties, Paris, 2009. 